\title{
Análise da efetividade constitucional do direito à educação em tempos de pandemia de Covid-19 no Brasil
}

\author{
Analysis of the constitutional effectiveness of the right to education in times of the Covid-19 \\ pandemic in Brazil \\ Análisis de la efectividad constitucional del derecho a la educación en tiempos de la pandemia \\ Covid-19 en Brasil
}

Recebido: 08/09/2021 | Revisado: 14/09/2021 | Aceito: 13/01/2022 | Publicado: 14/01/2022

\author{
Hugo Sarmento Gadelha \\ ORCID: https://orcid.org/0000-0001-9414-0554 \\ Universidad del Museo Social Argentino, Argentina \\ E-mail: hugoscurso@uol.com.br \\ Hiran Mendes Castro Filho \\ ORCID: https://orcid.org/0000-0002-1418-159X \\ Universidad del Museo Social Argentino, Argentina \\ E-mail: hirancastro@gmail.com \\ Agílio Tomaz Marques \\ ORCID: https://orcid.org/0000-0001-8364-5063 \\ Universidade Federal de Campina Grande, Brasil \\ E-mail: agiliotomaz@hotmail.com \\ Suzana Araújo dos Santos \\ ORCID: https://orcid.org/0000-0001-5955-9421 \\ Universidade Federal de Campina Grande, Brasil \\ E-mail: suzana.santos2007@yahoo.com.br \\ Michael Jhonatas Calado de Oliveira \\ ORCID: https://orcid.org/0000-0002-9737-1013 \\ Instituto Federal da Paraíba, Brasil \\ E-mail: kalado2354@hotmail.com \\ Matheus Matos Ferreira Silva \\ ORCID: https://orcid.org/0000-0002-3905-1951 \\ Universidade Federal de Campina Grande, Brasil \\ E-mail: matheusmatosfs@gmail.com \\ José Cândido da Silva Nóbrega (in Memoriam) \\ ORCID: https://orcid.org/0000-0002-0976-3763 \\ Universidade Federal de Campina Grande, Brasil \\ E-mail: jcandidosn@uol.com.br \\ Hellita do Nascimento Fernandes \\ ORCID: https://orcid.org/0000-0002-8212-7165 \\ Universidade Federal de Campina Grande, Brasil \\ E-mail: hellitanascimento2@gmail.com \\ Francilene Ferreira Gomes \\ ORCID: https://orcid.org/0000-0002-1156-3728 \\ Universidade Federal da Paraíba, Brasil \\ E-mail: gomes.fran11@gmail.com
}

\begin{abstract}
Resumo
O presente estudo abordará questões relacionadas ao direito constitucional no que tange a educação em tempos de pandemia de Covid-19 no Brasil, nesse contexto, esse direito é previsto como um direito social fundamental, onde o Estado, a família e a sociedade têm a incumbência de incentivar e promover a educação, visando o pleno desenvolvimento do cidadão. Em face dessa perspectiva, essa pesquisa tem como objetivo fazer uma análise sobre os principais problemas ocasionados pela situação pandêmica que interferem na garantia do direito à educação no território brasileiro, tendo por base as dificuldades pelas quais perpassam a parcela da população mais vulnerável para ter acesso à educação e utilizar a modalidade de ensino remoto, que se tornou uma opção destinada a assegurar o cumprimento do ano letivo escolar de 2020. Metodologicamente para a realização dessa pesquisa, foi adotado o método dedutivo, o qual foi realizado através de análise de dados bibliográficos de natureza qualitativa e documental. A partir dos resultados encontrados, considera-se que a efetivação constitucional do direito a educação, foi mitigada para a parcela da população que não apresenta as condições necessárias para que sejam utilizadas as tecnologias para se ter acesso ao ensino remoto. Dessa forma, devido a acentuada desigualdade social e econômica que existe no país,
\end{abstract}


os estudantes mais pobres são os mais afetados no quesito do acesso à educação no período da pandemia, principalmente pelo fato dessa grande parcela não dispor de internet e de tecnologias de acesso para seu uso.

Palavras-chave: Direito à Educação; Pandemia; Ensino Remoto.

\begin{abstract}
This study will address issues related to constitutional law regarding education in times of the Covid-19 pandemic in Brazil, in this context, this right is provided as a fundamental social right, where the State, the family and society are responsible to encourage and promote education, aiming at the full development of the citizen. In view of this perspective, this research aims to analyze the main problems caused by the pandemic situation that interfere in the guarantee of the right to education in the Brazilian territory, based on the difficulties faced by the most vulnerable portion of the population to have access to education and use the remote teaching modality, which became an option to ensure compliance with the 2020 school year. Methodologically, to carry out this research, the deductive method was adopted, which was carried out through the analysis of bibliographic data of a qualitative and documentary nature. From the results found, it is considered that the constitutional realization of the right to education was mitigated for the portion of the population that does not have the necessary conditions for the use of technologies to have access to remote education. Thus, due to the marked social and economic inequality that exists in the country, the poorest students are the most affected in terms of access to education during the pandemic period, mainly because this large portion does not have internet and access technologies for its use.
\end{abstract}

Keywords: Right to Education; Pandemic; Remote Learning.

\title{
Resumen
}

Este estudio abordará cuestiones relacionadas con el derecho constitucional en materia de educación en tiempos de la pandemia Covid-19 en Brasil, en este contexto, este derecho se prevé como un derecho social fundamental, donde el Estado, la familia y la sociedad son responsables de alentar y promover educación, orientada al pleno desarrollo del ciudadano. En esta perspectiva, esta investigación tiene como objetivo analizar los principales problemas provocados por la situación pandémica que interfieren en la garantía del derecho a la educación en el territorio brasileño, a partir de las dificultades que enfrenta la parte más vulnerable de la población para acceder a la educación y utilizar la modalidad de enseñanza a distancia, que se convirtió en una opción para asegurar el cumplimiento del año escolar 2020. Metodológicamente, para llevar a cabo esta investigación se adoptó el método deductivo, el cual se llevó a cabo mediante el análisis de datos bibliográficos de carácter cualitativo y carácter documental. De los resultados encontrados, se considera que la realización constitucional del derecho a la educación fue mitigada para la porción de la población que no cuenta con las condiciones necesarias para el uso de tecnologías para acceder a la educación a distancia. Así, debido a la marcada desigualdad social y económica que existe en el país, los estudiantes más pobres son los más afectados en cuanto al acceso a la educación durante el período pandémico, principalmente porque esta gran parte no cuenta con internet y tecnologías de acceso para su uso.

Palabras clave: Derecho a la educación; Pandemia; Aprendizaje Remoto.

\section{Introdução}

O direito a educação é um direito constitucional efetivado na Constituição Federal de 1988 e transmite a ideia de que o Estado é obrigado a garantir que todos tenham direito à uma educação igualitária desde o ensino fundamental até o ingresso no ensino superior público (Machado, 2020).

Porém, diante da situação pandêmica, várias medidas de segurança tiveram que ser colocadas em prática para tentar frear o contágio do vírus e entre essas medidas está o ensino de educação de forma remota, que tem sido promovido para dar continuidade ao ano letivo, porém, o que acontece é que no Brasil muitos alunos do ensino público que estão em situação vulnerável não têm acesso a esse tipo de sistema de ensino.

Diante dessa problemática, surge a seguinte indagação: A Carta maior tem como garantia a promoção e a efetivação das políticas públicas para promover o direito à educação de forma isonômica, entretanto, em face dessa pandemia de Covid19, será que o acesso à educação está sendo oferecido de forma igualitária?

Nesse sentido, essa pesquisa tem como objetivo principal, analisar os impactos provenientes da situação pandêmica na garantia constitucional da promoção do direito à educação no Brasil, tendo por base as especificidades que grande parte da população enfrenta em relação ao acesso a novas tecnologias para poder ter garantido seu direito a educação. 
Metodologicamente, nessa pesquisa, adota-se os moldes do método de abordagem dedutivo, através da análise da garantia do acesso ao direito a educação e sua efetividade de aplicação como direito constitucional no contexto da pandemia da Covid-19, onde o estudo se desenvolve por meio da pesquisa de dados bibliográfica de cunho qualitativo, fundamentando-se na abordagem dialética através de análise de artigos, revistas, livros, teses, dissertações e pesquisas.

Tendo por base também o estudo amparado na pesquisa documental realizado através da análise de documentos legais emitidos para normatizar a educação em tempos de pandemia e em autores da bibliografia especializada.

Para melhor compreensão, esta pesquisa organiza-se precipuamente em fazer uma análise sobre o direito constitucional a educação, em seguida é feito um estudo sobre a aplicação da educação em tempos de pandemia e por fim, será analisado as políticas públicas que são aplicadas para efetivação do direito a educação durante a pandemia da Covid-19 no Brasil.

Por fim, essa pesquisa torna-se imprescindível principalmente, por fazer uma análise sobre a atual sobre a aplicação do direito constitucional e sua efetividade na aplicação de medidas para a educação no Brasil nesse período de pandemia de Covid-19, o qual servirá de fonte de pesquisa para trabalhos posteriores.

\section{Direito à educação na Constituição Federal de 1988}

O direito à educação possui grande relevância como direito social e está positivado no artigo $6^{\circ}$ da Constituição Federal de 1988 "são direitos sociais a educação, a saúde, a alimentação, o trabalho, a moradia, o transporte, o lazer, a segurança, a previdência social, a proteção à maternidade e à infância, a assistência aos desamparados, na forma desta Constituição" (Brasil, 1988).

Tal conjuntura, é prevista na Carta Magna que inovou em seu artigo $6^{\circ}$ e traz um rol dos direitos sociais que funcionam como prestação positiva do estado e devem ser garantidos e aplicados pelo estado social de direito e devem ser concretizados na perspectiva de uma isonomia social em prol da busca de condições de vidas melhores e mais adequadas para que o cidadão possa garantir um futuro melhor (Lenza, 2019).

Nesse caso, esses direitos são previstos nessa teia social como normas cogentes, ou seja, fazem parte da ordem pública, que não podem ser anulados independente do interesse dos legisladores, pois possuem um caráter muito eficaz em atuar como norma garantidora dos direitos da educação no país (Tavares, 2020).

Tais medidas operantes são essenciais para assegurar, que a educação no Brasil, obedece ao princípio da gratuidade, quando oferecida em estabelecimentos oficiais (inc. IV do art. 206). Isso significa dizer que é vedado ao Poder Público cobrar do indivíduo pelo oferecimento da educação em estabelecimentos próprios (Brasil, 1988).

Nessa perspectiva, a Constituição ressalva no artigo 208 que a oferta de ensino advém de um direito que deve ser oferecido de forma gratuita, que tem caráter obrigatório, onde o Estado é obrigado a prestar atendimento permanente ao educando, durante todas as fases da educação, através de programas de políticas de oferta de material didático escolar, transporte, alimentação e assistência à saúde, incluindo a prestação de educação nos períodos noturnos (Brasil, 1988).

Apesar de não estar de acordo com a realidade atual do país, a lei maior brasileira determina em seu artigo 205 que a educação deve ser oferecida como um direito de todos ao longo da vida, visando ao pleno desenvolvimento da pessoa, seu preparo para o exercício da cidadania e sua qualificação para o trabalho (Brasil, 1988).

Em complemento a Constituição do Brasil discorre no artigo 210, que sejam fornecidos conteúdos mínimos para o ensino fundamental, de maneira que possa ser assegurado a formação básica comum e respeito aos valores culturais e artísticos, nacionais e regionais. Ou seja, para a promoção do direito à educação, haverá determinados objetivos em comum, estabelecidas pelo Estado, para o interesse geral da população. 
A Carta maior, no seu artigo 214, V, estabelece a realização da promoção humanística, científica e tecnológica, com o objetivo de que o Estado deve promover meios para articular e executar essas realizações com o ensino que há de oferecer para a população.

Apesar da Constituição efetivar e garantir diversas formas de promoção da educação, o padrão de qualidade a ser aplicado no ambiente escolar não foi descrito, o qual foi definido pela Lei de Diretrizes e Bases da Educação Nacional (Lei ${ }^{\circ}$ 9394/96) que aduz em seu artigo $4^{\circ}$ que o estado deve assegurar os meios para que seja oferecida uma garantia de prestação de ensino escolar público, onde deve ser oferecido o ensino com os padrões de qualidade de ensino, que possa ser oferecido por aluno, insumos indispensáveis que servem de auxílio ao processo de desenvolvimento de ensino e aprendizagem (Brasil, 1996).

Em conclusão, o direito a educação é assegurado pela Carta Magna, como um direito social que integra outros direitos como, a saúde, alimentação, lazer e visa, a inserção futura do estudante no mercado de trabalho, devendo ser oferecido pelo estado de forma gratuita e também devem ser oferecidos subsídios para os cidadãos ter acesso as políticas de educação.

\section{O direito à educação e os desafios em tempos de pandemia de Covid-19}

Devido a situação de emergência global, decorrente da pandemia da Covid-19, foram impostas uma série de medidas para a educação em todo o mundo, onde acarretou na ocorrência de vários problemas que desencadearam uma crise educacional enfrentada por diversos países, inclusive pelo Brasil, o qual possui investimentos e vagas insuficientes nas escolas, aliados a deterioração, evasão e altas taxas de repetência e desistência escolar, além do analfabetismo (Silva, 2020).

Percebe-se que entre as áreas mais atingidas pela pandemia está a educação, onde escolas e instituições de ensino tiveram suas atividades temporariamente encerradas e foram posteriormente fechadas em prol do distanciamento social, sendo essa medida necessária para conter o contágio do vírus, onde a modalidade de Educação à Distância foi a opção mais viável para garantir o cumprimento dos calendários escolar do ano de 2020.

Acontece que a situação pandêmica coloca em risco a efetivação do direito a educação que fica ainda mais comprometido em face das mudanças instituídas pelas normativas de segurança que foram elaboradas para diminuir a disseminação do vírus. E a partir da instituição do ensino remoto, surgiram algumas dificuldades para uma grande parcela da população acostumar-se com as mudanças para que fosse possível ter acesso à educação (Almeida, 2020).

Em síntese, através do estudo é importante destacar que a pandemia da provocou inúmeras mudanças nas vidas das pessoas e em consequência a rede de ensino também vem enfrentado diversos entraves para realizar atividades pedagógicas remotas, além disso, diversos estudantes nem sequer tem acesso a uma tecnologia adequada para o acompanhamento dessas aulas remotas, destacando assim a precariedade do direito a educação principalmente para os alunos da rede pública.

\section{Ações governamentais para efetivação da educação no contexto da pandemia da Covid 19}

A Organização Mundial da Saúde (OMS), decretou no início do mês de março do ano de 2020, as orientações que deveriam ser seguidas como meio de enfrentamento a pandemia da Covid-19 e declarou a necessidade de implantação das medidas de distanciamento social que dependem da urgência e necessidade da situação epidemiológica (Brasil, 2020).

Nesse sentido, e diante do estado de urgência, houve a necessidade de ser decretada uma normativa como forma da primeira iniciativa tomada pelo Governo Federal que foi a edição da Portaria 343/2020 no dia 17 de março que autorizava em função do caráter excepcional, a substituição das aulas presenciais por aulas online, onde pudessem obedecer às medidas de distanciamento social.

A priori, essas mudanças no sistema educacional para se adequar ao ensino remoto em um país como o Brasil, que é marcado profundamente pelas desigualdades sociais torna-se um grande desafio mais do que significativo, para que seja 
oferecido o direito à educação, que historicamente é restrito à uma determinada parcela da sociedade de forma igualitária (Jakimiui, 2020).

Dessa forma, no campo da educação, essas normatizações governamentais para que seja proporcionada a educação nesse período de pandemia, evidenciam projetos de formação em disputa, sendo a primeira questão que deve ser levada em consideração a forma restrita de educação apresentada pelos documentos normativos que foram constituídas a partir de uma perspectiva totalmente conteudista (Jakimiui, 2020).

Esses procedimentos são totalmente contraditórios ao papel da escola que tem o papel de garantir a promoção de acesso a outros direitos sociais, principalmente daqueles relacionados à saúde e à alimentação, os quais tem a maioria dessas políticas implementadas por meio do Programa Nacional de Alimentação Escolar (PNAE) através de ações intersetoriais entre o Ministério da Educação e o Ministério da Saúde, como por exemplo, o Programa Saúde Escolar (PSE) (Mec, 2020).

Ademais, essa aplicação conteudista da educação por meio da adoção do ensino remoto emergencial tem, inclusive, provocado implicações da implementação dessas políticas, pois em um país marcado por grandes desigualdades educacionais e com aproximadamente 1,9 milhões crianças e jovens fora da escola segundo dados do (PNAD, 2017) o implementar o ensino remoto emergencial vai contribuir com a precarização e substituição permanente do ensino presencial pelo ensino não em sala de aula física que implica no barateamento e sucateamento da educação (Bandeira \& Pastin, 2020).

Tal afirmativa pode ser confirmada através um estudo que foi feito pelo Comitê Gestor da Internet no Brasil (CGI.br) em 2018, nomeado de Pesquisa (TIC Domicílios), onde através da pesquisa foi possível verificar, que um grande número dos cidadãos brasileiros só tem acesso à internet através do próprio celular, a principal razão relatada na pesquisa foi a falta de disponibilidade de um computador, tablet ou notebook, o que prejudica a realização de atividades que são oferecidas de forma online.

Consoante a Pesquisa TIC Domicílios, na parcela da população onde a renda familiar é inferior até 1 salário mínimo, que representa um total de $78 \%$ das pessoas que podem acessa à internet, estas usam por meio apenas do aparelho celular, onde foi verificado que apenas 39\% dos domicílios brasileiros possuem um computador (CGI.br, 2018).

Além da falta de tecnologia adequada para o uso da internet, outro fator que não contribui para a promoção do online no Brasil é a falta de internet de qualidade e principalmente de aparelhos eletrônicos para que os estudantes possam direito a educação nesse momento atual que perpassa o país, fatores que tem ajudado a desmotivar vários estudantes que já vivem em situação de miséria, e isso tem feito que, tanto professores quanto alunos precisem muitas vezes sair de casa para dar continuidade à seus afazeres e estudos, levando-os a um possível contágio do vírus que tentamos evitar através do distanciamento social (Machado, 2020).

Dentro dessa discussão, a questão central que deve ser considerada, é indubitavelmente sobre o contexto social atual e a forma como o conhecimento, a educação e a escola neste contexto devem ser realizadas no futuro. Já que escola possui um compromisso com a sociedade, que não se restringe à simples transmissão e cobrança de conteúdo, e quanto a questão das desigualdades sociais no Brasil, essas são tão constrangedoras que em meio a pandemia muitas famílias continuarão indo até as escolas para acessar os programas sociais, sobretudo, àqueles relacionado à alimentação escolar (Jakimiui, 2020).

É perceptível que a comunidade escolar como um todo vem sofrendo as consequências dos mais variados tipos desde o início da implementação das aulas virtuais em substituição às aulas presenciais, e em consonância torna-se necessária as pesquisas e estudos sobre a falha na efetividade do direito constitucional no fornecimento à educação para as crianças e adolescentes em idade escolar.

E em decorrência dessa falha da educação no Brasil os estudantes, principalmente aqueles que dependem de escolas públicas, se viram diante de uma nova realidade que em que o acompanhamento das aulas se torna ainda mais desigual e de 
grande dificuldade para muitos a partir da necessidade do acesso à aparelhos eletrônicos e internet, recursos que estão fora do alcance de muitos (Machado, 2020).

Em conclusão, as ações governamentais que foram desenvolvidas em caráter emergencial devido a pandemia da Covid-19, não possuem em sua totalidade o dever de oferecer um ensino remoto igualitário, e isso ocorre principalmente por falta de estratégias mais eficazes por parte do governo federal para que sejam efetivados o direito a educação no Brasil.

\section{Resultados e Discussão}

Através das medidas adotadas para o ensino remoto emergencial no contexto da pandemia da Covid-19 no Brasil, surgiram vários fatores que nos colocam diante da necessidade de produzir conhecimento e de discutir crítica e profundamente em todos os espaços epistemológicos sobre o contexto que estamos vivendo e sobre os desdobramentos nas formas de pensar e promover o ensino igualitário no Brasil (Jakimiui, 2020).

Isso se dá principalmente, devido à falta de equipamentos tecnológicos por parte da população, o que dificulta a promoção da educação em espaços fora do ambiente escolar, além do fato dos alunos dependeram por muitas vezes da escola para fazerem suas refeições e praticar atividades de esporte, cultura e lazer.

Dessa forma, os estudantes que vivem em condições mais preconizadas, são os mais impossibilitados de usufruir da educação a distância, e ainda sofrerão futuramente os efeitos da precariedade no seu acesso e falta de outras políticas públicas como acesso a alimentação e saúde. Ademais, esses estudantes terão que complementar a carga horária que falta após o retorno das aulas de forma presencial, de maneira que atrasará a conclusão do curso, afetando também a entrada no mercado de trabalho (Almeida, 2020).

Isso demonstra a fragilidade da efetividade da garantia constitucional do direito social a educação em toda sua totalidade nesse contexto da pandemia da Covid-19, pois são vários fatores que interferem na implantação das aulas online, de forma que nem todos os alunos tem acesso a assistir aula através da tecnologia alternativa ao ensino presencial que é através da internet.

Além do mais, é valido discorrer que no país, há uma grande exclusão gerada pelo analfabetismo digital, em consequência principalmente porque uma parcela da população ainda não tinha adquirido conhecimentos básicos de acesso a novas tecnologias, onde não adquiriram habilidades para usar internet, e assim, entender e usar as informações em vários formatos (Gomez, 2017).

Entretanto, por causa do fechamento de escolas em razão do distanciamento social, que é de extrema necessidade para conter o avanço do vírus, a modalidade de ensino remoto se tornou a opção mais viável, designada para cumprir os calendários escolares do ano de 2020, no entanto, foi possível verificar que a rede pública também tem enfrentado dificuldades para desenvolver as atividades através do uso das plataformas digitais.

\section{Considerações Finais}

Através do estudo empreendido, foi possível constatar que as iniciativas governamentais apresentadas diante do contexto de pandemia não são suficientes e eficazes para efetivar o direito à educação diante dessa situação pandêmica.

Dessa forma, as normatizações expedidas pelo Governo Federal não se apresentam estrategicamente eficazes, não só pelo fato de se tratarem de normas legais impraticáveis no contexto educacional brasileiro reforçando ainda mais as desigualdades sociais que existem no Brasil, mas também por deixar a educação exposta às políticas educacionais que caminham na direção da precarização da educação pública e retrocedem na garantia da direito à educação.

É evidente, que o contexto da pandemia, apresenta vários desafios de vida em sociedade, onde a educação e a escola enquanto espaço social de convivência diária se apresenta como espaço de redução das desigualdades sociais. Nesse sentido 
não basta apenas pensar na garantia da educação, mas sobretudo, pensar acerca das dimensões éticas, estéticas e ontológicas em torno de qual educação está se requerendo o direito.

Através do estudo empreendido, é possível constatar que as iniciativas governamentais apresentadas diante do contexto de pandemia, não só não avançam na garantia do direito à educação, como fazem o seu contrário, retrocedem, pois não se apresentam de forma eficaz para que haja a promoção da educação igualitária.

Em face dessa problemática, é preciso que sejam criadas novas estratégias por parte do Governo Federal e Ministério da Educação, para que sejam desenvolvidas atividades complementares, principalmente para aqueles estudantes que não tiveram acesso ao ensino remoto, para que possam recuperar de alguma forma o déficit da falta de acesso a tecnologias e internet para o acesso à educação igualitária.

\section{Referências}

Almeida, F. T. (2020). A pandemia de Covid-19: Reflexos na garantia do direito a educação. Pensar Acadêmico, Manhuaçu, 18(5), dezembro, número especial,

Bandeira, O., \& Pastin, A., (2020). Como o ensino a distância pode agravar as desigualdades agora. Nexo Jornal Ltda. https://www.nexojornal.com.br/ensaio/debate/2020/Como-o-ensino-a-dist\%C3\%A2ncia-pode-agravar-as-desigualdades-agora.

Brasil. (1988). Constituição da República Federativa do Brasil de 1988. Brasília, DF: Presidência da República. http://www.planalto.gov.br/ccivil_03/Constituicao/Constituiçao.htm.

Brasil. (1996). Lei no 9.394, de 20 de dezembro de 1996. Estabelece as diretrizes e bases da educação nacional. Brasília, DF: Presidência da República. http://www.planalto.gov.br/ccivil_03/leis/19394.htm.

Brasil. (2020). Lei n 14.040 , de 18 de agosto de 2020. Brasília, DF: Presidência da República. http://www.planalto.gov.br/ccivil_03/_Ato20192022/2020/Lei/L14040.

Comitê Gestor da Internet no Brasil (CGI.br). (2016). Pesquisa sobre o uso das tecnologias de informação e comunicação nos domicílios brasileiros: TIC domicílios. São Paulo: Núcleo de Informação e Coordenação do Ponto BR, 2017. E-book (430 p.). https://cetic.br/pt/publicacao/pesquisa-sobre-o-usodastecnologias-de-informacao-e-comunicacao-nos-domicilios-brasileiros-tic-domicilios $2016 /$.

Jakimiui, L. C. V. (2020). O direito à educação no contexto da pandemia da Covid-19 no Brasil: Projetos de formação em disputa. Revista Interinstitucional Artes de Educar. 6, 94-117: "Educação e Democracia em Tempos de Pandemia”. 10.12957/riae.2020.51007.

Lenza, P. (2019). Direito constitucional esquematizado. (23a ed.), Saraiva Educação, 2019.

Machado, C. M., \& Righi, M. D. L., \& Shirmer, C. (2020). Uma análise constitucional sobre o direito a educação em tempos de distanciamento social causado pela pandemia da Covid-19. $17^{\mathrm{a}}$ Entrementes Semana Acadêmica Da Fadisma.

MEC. Ministério da Educação. Coronavírus. Monitoramento nas Instituições de Ensino. (2020). Ações Do Mec Em Resposta À Pandemia De COVID-19. https://www.gov.br/mec/pt-br/coronavirus.

Silva, V, D., \& Sousa, C, F. (2020). Direito a educação igualitária em tempos de pandemia: Desafios, possibilidades e perspectivas no Brasil, $\mathrm{n}^{\circ}$ 4, RJLB.

Pnad. Pesquisa Nacional por Amostra de Domicílios Contínua. (2017). https://www.ibge.gov.br/estatisticas/multidominio/condicoes-de-vida-desigualdade-epobreza/17270- pnad-continua.htmledicao $=21073 \& \mathrm{t}=$ sobre

Tavares, A. R. (2020). Curso de direito constitucional. (18a ed.), Saraiva Educação. 